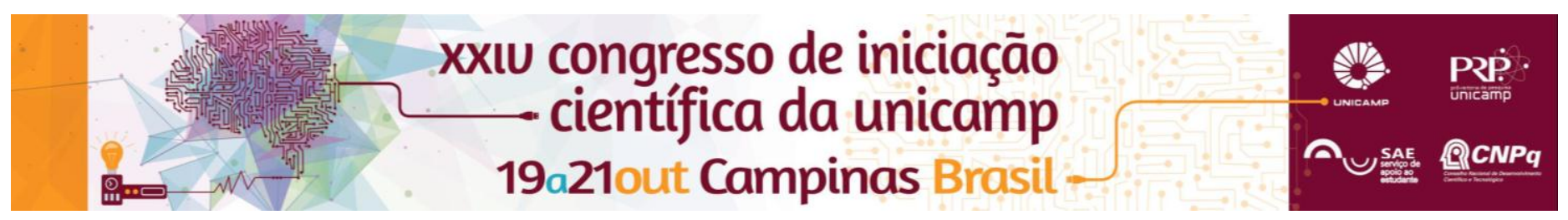

\title{
APLICAÇÃo de REsíduos de BORRACHA DE PNEU NO CONCRETO LEVE AUTO ADENSÁVEL
}

\author{
Nathalie de O. Hernandes, Prof. Dra. Luísa A. G. Barbosa.
}

\section{Resumo}

Para fins estruturais ou de vedação, os concretos leves podem ser utilizados na construção civil, permitindo ganhos na redução do peso das estruturas. Tornou-se possível a formulação de concretos fluidos, a partir do uso de agregados leves, que apresentam excelentes desempenhos físicos e mecânicos. Nesta pesquisa, foram realizados ensaios reológicos, de densidade, resistências à compressão e à tração por compressão diametral, absorção acústica e microestrutura.

\section{Palavras-chave:}

Concreto leve auto adensável, Resíduos de borracha de pneu, Materiais alternativos.

\section{Introdução}

O concreto leve auto adensável (CLAA) é caracterizado pela alta fluidez e baixa densidade. Frente ao exposto, produziram-se um traço de referência e sete traços contento pó de borracha de pneu. Avaliaram-se suas principais propriedades físicas e mecânicas, assim como absorção acústica e microestrutura.

\section{Resultados e Discussão}

Tabela 1. Valores dos ensaios reológicos e densidade.

\begin{tabular}{c|c|c|c|c}
\hline Traço & $\begin{array}{c}\text { Slump } \\
(\mathbf{m m})\end{array}$ & $\begin{array}{c}\text { Caixa "L" } \\
(\mathbf{H 2} / \mathbf{H 1} \mathbf{)}\end{array}$ & $\begin{array}{c}\text { Funil "V" } \\
(\mathbf{s})\end{array}$ & $\begin{array}{c}\text { Densidade } \\
\left(\mathbf{K g} / \mathbf{m}^{\mathbf{3}}\right)\end{array}$ \\
\hline Ref & 560 & 0,86 & 5 & 2132 \\
\hline$T 1(5 \%$ borracha $)$ & 560 & 0,89 & 3,5 & 1882 \\
\hline$T 2(7,5 \%$ borracha $)$ & 550 & 0,82 & 4,5 & 1779 \\
\hline$T 3(10 \%$ borracha $)$ & 590 & 0,90 & 3,5 & 1830 \\
\hline$T 4(12,5 \%$ borracha $)$ & 590 & 0,88 & 5,0 & 1694 \\
\hline$T 5(15 \%$ borracha $)$ & 550 & 0,94 & 4,0 & 1676 \\
\hline$T 6(17,5 \%$ borracha $)$ & 580 & 0,87 & 5,0 & 1547 \\
\hline$T 7(20 \%$ borracha $)$ & 600 & 0,82 & 5,5 & 1574 \\
\hline
\end{tabular}

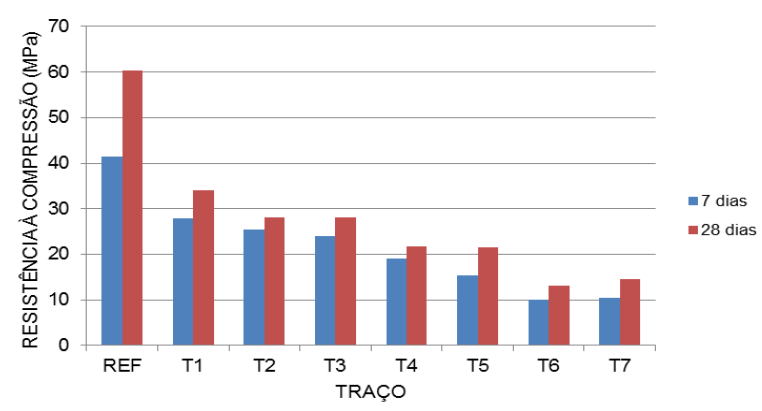

Figura 1. Valores de resistência à compressão.

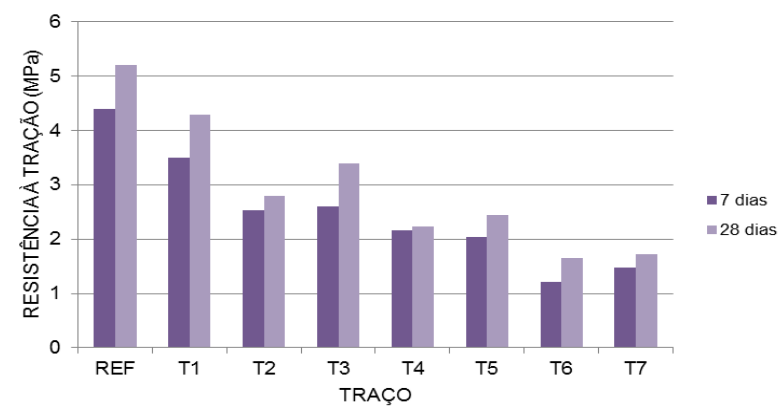

Figura 2. Valores de resistência à tração.

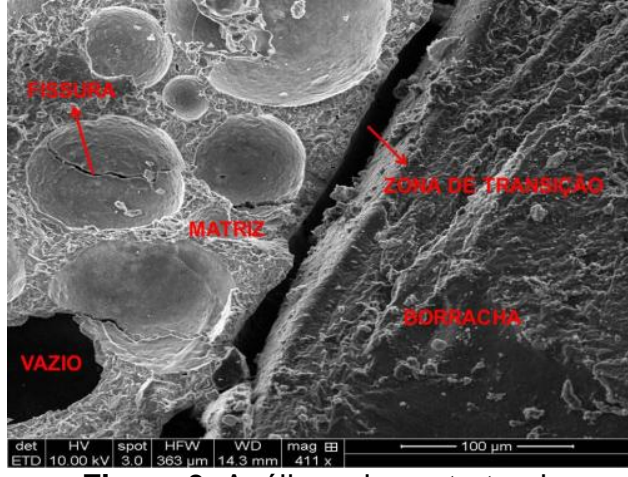

Figura 3. Análise microestrutural.

Tabela 2. Valores da absorção acústica.

\begin{tabular}{c|c}
\hline Traço & Absorção acústica (a) \\
\hline Ref & 0,58 \\
\hline$T 1$ & 0,60 \\
\hline$T 2$ & 0,38 \\
\hline$T 3$ & 0,40 \\
\hline$T 4$ & 0,38 \\
\hline$T 5$ & 0,18 \\
\hline$T 6$ & 0,82 \\
\hline$T 7$ & 0,58 \\
\hline
\end{tabular}

Pode-se verificar que quanto maior o teor de borracha na mistura, menores são a densidade e as resistências mecânicas, pois há um aumento da porosidade. Houve picos de absorção acústica nas diferentes misturas, isto ocorre devido à porcentagem ideal de borracha na mistura.

\section{Conclusões}

Podemos concluir que os CLAA atenderam aos parâmetros de auto adensibilidade, leveza e conforto térmico, entretanto há uma queda das resistências mecânicas.

\section{Agradecimentos}

À UNICAMP e ao CNPq, pelo apoio e fomento. À Silicon, Cinexpan e BASF, pelos materiais concedidos.

Referências bibliográficas

Borja, E.V. Efeito da adição da argila expandida e adições minerais na formulação de concretos estruturais leves autoadensáveis. Tese de doutorado. Universidade Federal do Rio Grande do Norte. Natal, 2011. 